\title{
CERVICAL PAP SMEAR PATTERN- COMPARISON OF HOSPITAL AND SCREENING CAMP POPULATION
}

\author{
Neeraj B1, Sunitha Balakrishnan², Sankar $S^{3}$
}

${ }_{1}^{1}$ Resident, Department of Pathology, Government Medical College, Kottayam, Kerala, India.

${ }^{2}$ Associate Professor, Department of Pathology, Government Medical College, Kottayam, Kerala, India.

3 Professor and HOD, Department of Pathology, Government Medical College, Kottayam, Kerala, India.

\section{ABSTRACT}

\section{BACKGROUND}

Cervical cancer is one of the leading causes of mortality and morbidity among women worldwide. In India it accounts for $25 \%$ of cancer deaths. Only limited number of studies are available on prevalence of cervical epithelial abnormalities, especially in Kerala. The objective of the study was to estimate the prevalence of cervical cytological pattern in central Kerala, so that appropriate screening strategies can be planned.

\section{MATERIALS AND METHODS}

A one-year descriptive study was conducted on cervical pap smears in study population groups: 1) camp population from various camps conducted in and around Kottayam and 2) hospital population and specimens received in the department of Pathology, Government Medical College, Kottayam during the study period of 12 months. Smears were assessed according to the revised Bethesda System 2014. A total of 240 cases of Pap smears were analysed in each group of population (hospital and screening camp).

\section{RESULTS}

The mean age of population in the present study was $48.20 \pm 10.224$ SD in camp and $48.23 \pm 11.339$ SD in hospital population. Majority belongs to the age group 41-50 years. In both, majority of the smears were negative for intraepithelial lesion or malignancy (NIL/M). Epithelial abnormality was seen in $1.25 \%$ cases (LSIL) of camp population \& $2.5 \%$ cases (ASC-US, LSIL and HSIL $0.80 \%$ each) of hospital population.

\section{CONCLUSION}

Our study shows a relatively low prevalence of cervical epithelial abnormality similar to developed countries. Pap smear is an effective screening procedure to detect cervical cytological abnormalities. Routine screening should be offered to all women above 21 years. It is recommended to improve awareness about disease among females.

\section{KEY WORDS}

Cytopathological Pattern; Pap Smears; Epithelial Abnormality; Screening Camp.

HOW TO CITE THIS ARTICLE: Neeraj B, Balakrishnan S, Sankar S. Cervical pap smear pattern- comparison of hospital and screening camp population. J. Evolution Med. Dent. Sci. 2019;8(08):484-488, DOI: 10.14260/jemds/2019/108

\section{BACKGROUND}

Cancer of uterine cervix is one of the leading cause of mortality and morbidity among women worldwide. ${ }^{1}$ It is the fourth most frequently occurring cancer affecting women after breast, colorectal and lung cancers; it is also the seventh most common type of cancer overall. Cervical cancer is the most common cancer among women in 2 out of the 12 Population Based Cancer Registries (PBCRs) in India, and has the second highest incidence rate after breast cancer in the rest of the PBCRs. ${ }^{2}$

It is estimated that in India about 126,000 new cases of cervical cancer occur annually, ${ }^{3}$ and usually $70 \%$ or more of these cases present in stage III or Higher at the time of diagnosis. Cancer of cervix has a long latent period of about 10 years. Cervical cancer starts as a precancerous lesion, called dysplasia also termed as cervical intraepithelial neoplasia (CIN).

'Financial or Other Competing Interest': None.

Submission 21-12-2018, Peer Review 07-02-2019,

Acceptance 14-02-2019, Published 25-02-2019.

Corresponding Author:

Neeraj B,

Resident, Department of Pathology,

Government Medical College, Kottayam, Kerala, India.

E-mail: neeraj087@gmail.com

DOI: $10.14260 /$ jemds $/ 2019 / 108$

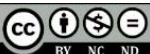

CIN starts at the transformation zone especially in relation to the squamous metaplasia and reserve cell hyperplasia. Cancer of cervix is readily preventable condition as it is easy to identify and treat its precursor lesions. The prognosis of cervical cancers worsens with the increasing stage of the disease. The early diagnosis and prompt specific treatment of pre-invasive or early stages of the disease reduces the prevalence of invasive carcinoma and improves the prognostic outcome of the patients. Unfortunately, most of the patients with early stages or pre-invasive carcinoma of cervix are asymptomatic and do not produce any specific clinical alterations of the cervix or may have only mild symptoms.

The screening for cervical cancer is based on the assumption that early detection may allow early treatment. It is a well-known fact that cytology based screening programs has resulted in dramatic reduction in the incidence and mortality of invasive cervical cancer in different countries of the world 4 . Cervical cancers are more common in developing countries. The high burden of cervical cancer in developing countries is largely due to a lack of effective screening programs.

Papanicolaou (Pap) smear testing is an effective method of detecting, preventing and delaying the progress of cervical cancer. This is because the Pap smear test detects cervical epithelial cell abnormalities which represent a spectrum of intraepithelial lesions, from mild-to-severe dysplasia to invasive cancer and facilitates early diagnosis of the condition 
with adequate and repetitive cytological screening. Even though liquid-based cytology is popular in the developed countries, in low resource settings, a conventional Pap smear test is the main screening system still following. It is important to know the overall scenario of epithelial cell abnormality in the Pap smear, especially in a developing country like India which accounts for quarter of the cervical cancer deaths. By knowing the patterns of premalignant and malignant lesions in an area, we can set up screening strategies and counsel women about the need of cervical screening.

Reporting of pap smears using revised Bethesda System has unified various overlapping terminologies and created a standardized framework for laboratory reports that includes a descriptive diagnosis and an evaluation of specimen adequacy. Only limited number of studies are available on prevalence of various cervical epithelial abnormalities in various populations in India, especially in Kerala. Hence, we have undertaken the present study using the revised Bethesda System, with the intention to estimate the prevalence of cervical epithelial abnormalities.

\section{MATERIALS AND METHODS}

\section{Type of Study}

Cross sectional analytical study.

\section{Study Period}

One year (from August 1, 2017 to July 31, 2018)

\section{Study Setting}

Department of Pathology, Government Medical College, Kottayam.

\section{Sample Size 5}

$$
\mathrm{n}=\frac{\left(\mathrm{z}_{1-\alpha / 2}+\mathrm{z}_{1-\beta}\right)^{2}\left[\mathrm{p}_{1}\left(1-\mathrm{p}_{1}\right)+\mathrm{p}_{2}\left(1-\mathrm{p}_{2}\right)\right]}{\left(\mathrm{p}_{1}-\mathrm{p}_{2}\right)^{2}}
$$

Where $Z_{1-\alpha / 2}=1.96$, the standard normal variate value at 95\% confidence interval $(\alpha=5 \%)$

$Z_{1-\beta}=0.842$, the standard normal variate value at $80 \%$ power

$\mathrm{P} 1=$ Proportion of epithelial abnormality in the institution = 0.01

P2 =Proportion of epithelial abnormality in the community= 0.05

Based on cervical smear records in our institution, $\mathrm{P} 1$ value is calculated. Since there was no previous data available for community P2 was calculated by assuming $5 \%$ prevalence.

Estimated risk difference $=-0.04$

Power (1- beta) $\%=80$

Alpha error $(\%)=5$

1 or 2 sided $=2$

Required sample size for each arm $=284$

From the above, the sample size of each population was found to be 284

However, sample size in each group will be limited by the size of camp population.

\section{Inclusion Criteria}

First 284 cases of pap smears obtained from each group of females aged more than 21 years are included in this study.

\section{Exclusion Criteria}

Pap smears taken on post hysterectomy patients, already known cases of carcinoma cervix are excluded.

\section{Study Procedure}

All the specimens are collected by the scrapings from the Squamo-columnar junction by Ayre's spatula and are evenly spread onto a glass slide, and immediately fixed by dipping in Coplin jars containing equal parts of 95\% ethyl alcohol and ether or any other cyto-fixatives. These specimens are received along with a requisition letter properly filled up with age, biopsy number. The specimens are then stained with Papanicolaou stain and analysed by the 2014 Bethesda system.

\section{Data Management and Analysis}

The data was entered in Microsoft excel and further statistical analysis was done using SPSS software (version 22).

\section{Statistical Methods}

1. Mean, frequency and proportion for:
a. Age.
b. Satisfactory and unsatisfactory smears.
c. Type of lesions.
d. Prevalence of epithelial abnormality.

Chi square test ( $\mathrm{p}$ value).

\section{RESULTS}

Cervical smears were obtained from both screening camp and hospital population. Screening camps for cervical cancer were conducted at 7 centres nearby Kottayam. The centres were located at Brahmamangalam, Karukachal, Veloor, Neelimangalam, Karapuzha, Changanassery and Fathimapuram. The camps were organised by nongovernmental associations, residential associations and National Health Mission. In some camps along with cervical cancer screening, medical camps were also conducted. In the camp patients were registered with basic details after which, a brief counselling was given regarding the benefits of cervical cancer screening. Cervical smears were made in the examination room provided using disposable Cusco's speculum and Ayre's spatula.

\section{No. of Attendees for each Camp are given below-}

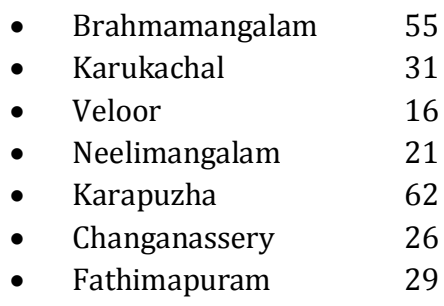

Majority of the patients who attended the camps were asymptomatic and a few showed symptoms. The most frequent symptom was discharge per vaginum, and lower abdominal pain. A few cases showed cervical erosion and one case show cervical polyp, which caused some difficulty in taking smears.

The smears from hospital were obtained from the outpatient clinic of obstetrics and gynaecology department, medical college Kottayam.

A total of 240 cervical pap smears were analysed in each study group (Camp and Hospital Population). 


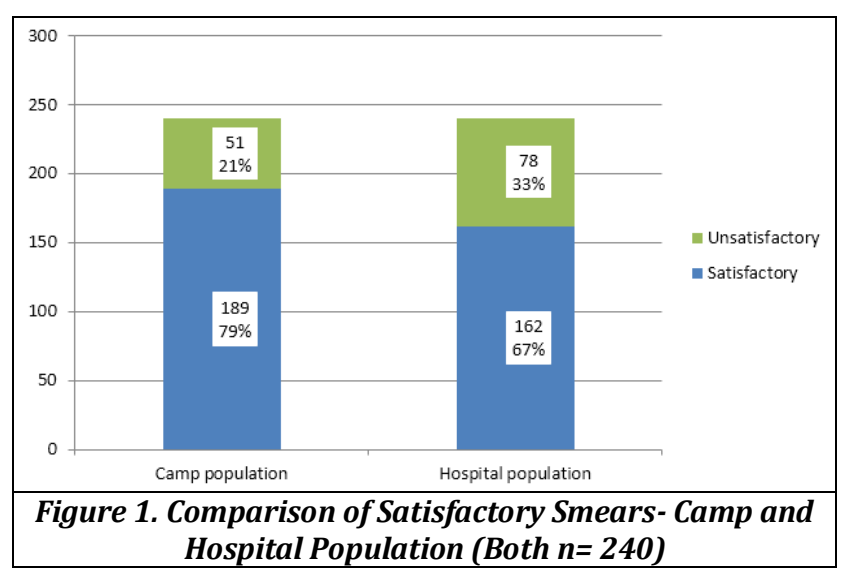

189 cases of camp and 162 cases of hospital population were found to be satisfactory. 51 cases of camp and 78 cases of hospital population were found to be unsatisfactory for evaluation. The main causes for unsatisfactory smears were inadequate squamous component or obscuring inflammation.

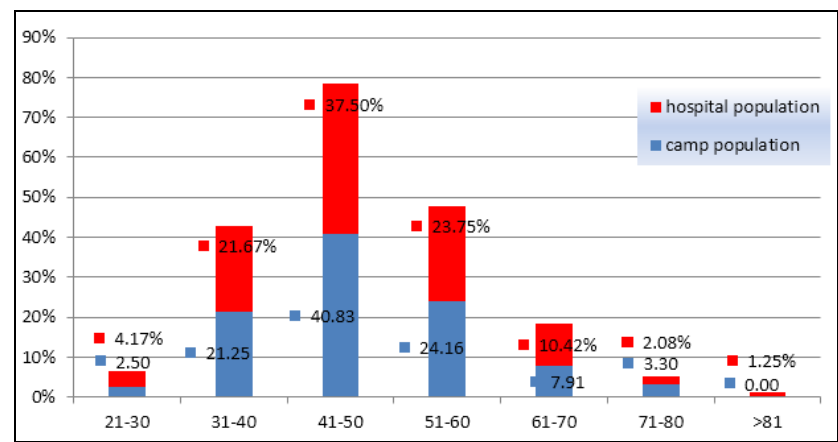

Figure 2. Age Wise Distribution of Camp and Hospital Population. (n= 240 Each)

The age group of the camp population ranges from 25 years to 75 years with the mean age of $48.20 \pm 10.224$ SD, majority belongs to the age group $41-50$ years $(40.83 \%)$. The age group of hospital population ranges from 21 years to 90 years with the mean age of $48.23 \pm 11.339$ SD, majority belongs to the age group 41-50 years (37.50).

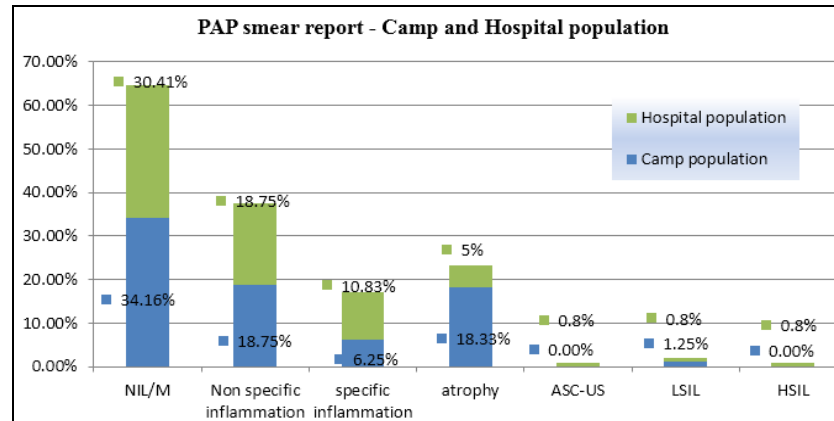

Figure 3. Pap Smear Report of Camp Population $(n=240)$ and Hospital Population $(n=240)$

Majority of the smears were negative for intraepithelial lesion or malignancy (NIL/M) comprises $34.16 \%$ and $30.41 \%$. (82 and 73 respectively) in each group. Nonspecific inflammation was seen in $18.75 \%$ cases of both populations. $6.25 \%$ cases of camp population and $10.83 \%$ cases of hospital population had specific infection suggestive of candidiasis or bacterial vaginosis.

$1.25 \%$ cases of camp population show epithelial abnormality, all are LSIL. $2.5 \%$ cases of hospital population showed epithelial abnormality, with ASC-US, LSIL and HSIL two cases each.

The $p$ value of association between LSIL in hospital and camp population was found to be 0.653 , which is statistically not significant. Since there was not even a single case of ASCUS, and HSIL were not detected in camp population, its association couldn't be checked.
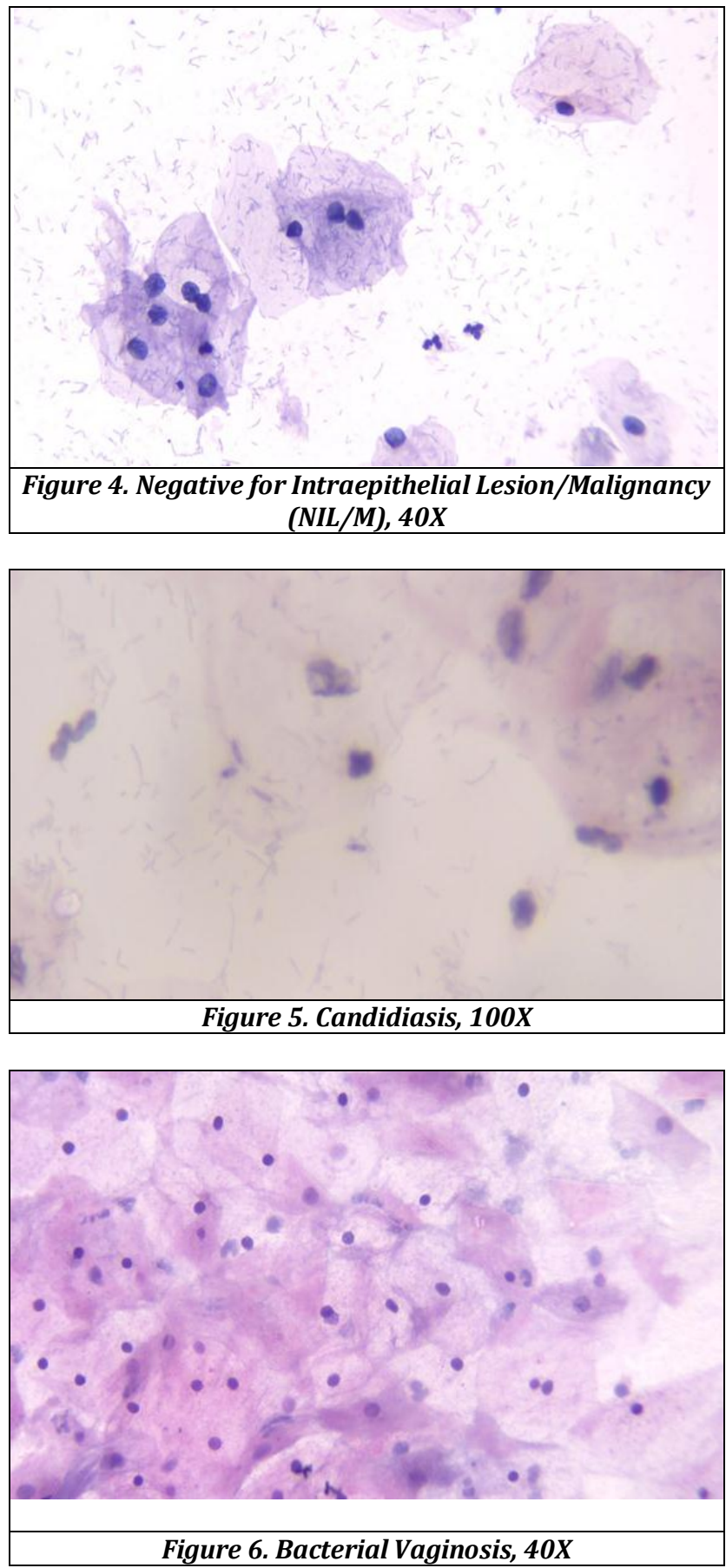

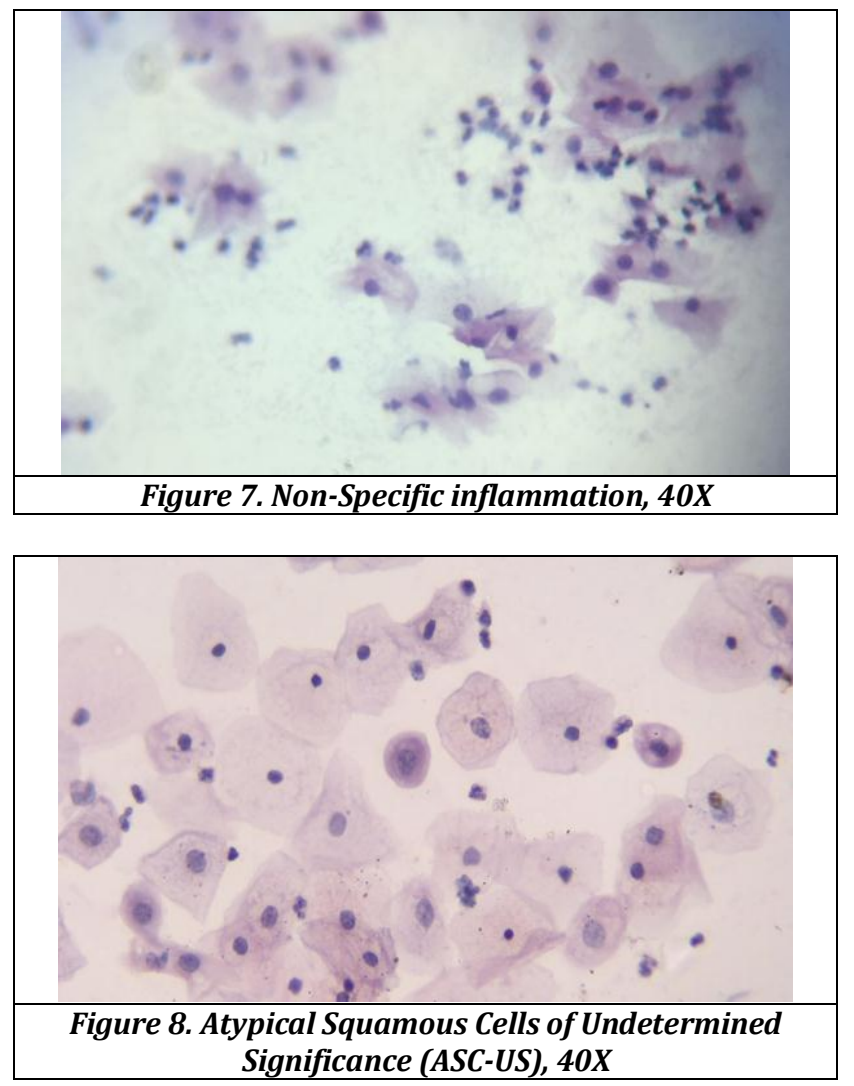

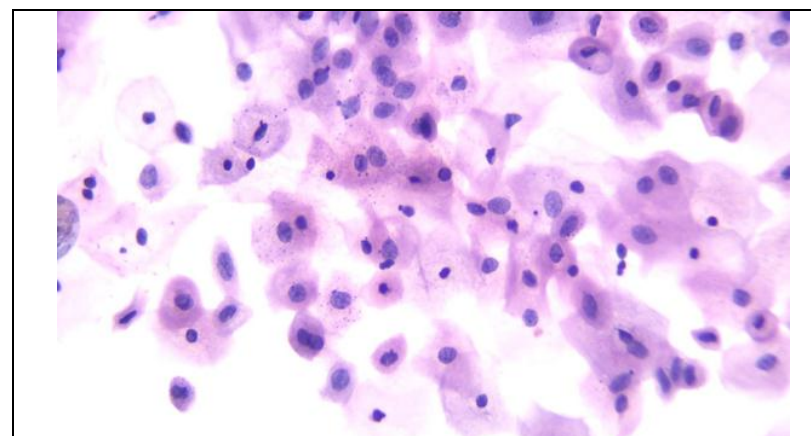

Figure 9. Low-Grade Squamous Intra-Epithelial Lesion (LSIL), 40X

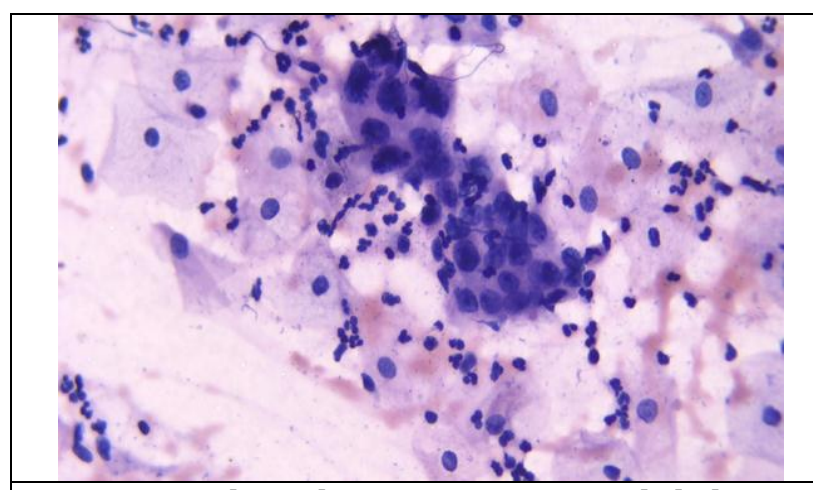

Figure 10. High-Grade Squamous Intra-Epithelial Lesion (HSIL), $40 \mathrm{X}$

\section{DISCUSSION}

Cervical cancer incidence has decreased to more than half in last three decades with widespread use of screening with cervical cytology. Pap smear-based screening methods have played a pivotal role in reducing cervical cancer incidence and mortality. Cervical epithelial abnormalities vary from country to country and also from regions to region of a country. According to different studies conducted in different parts of the world, Saudi Arabia shows a prevalence of $14.52 \%$ whereas Nepal shows prevalence of $1.14 \%$. There may be many factors which results in these variations including sample size, Selection criteria, Difference in population, Experience of the health professional collecting the PAP smears and attitude of the patients. The prevalence of epithelial abnormalities in different places of world and different regions of India is compared in Table 1 and 2.

\begin{tabular}{|c|c|c|c|c|c|c|c|c|c|}
\hline \multirow{2}{*}{ No } & \multirow{2}{*}{ Author } & \multirow{2}{*}{ Year } & \multirow{2}{*}{ Place } & \multirow{2}{*}{$\begin{array}{c}\text { No of } \\
\text { Patients }\end{array}$} & \multirow{2}{*}{$\begin{array}{c}\text { Total Prevalence } \\
\text { (\%) }\end{array}$} & \multicolumn{4}{|c|}{ Epithelial Abnormality (\%) } \\
\hline & & & & & & ASC-US & LSIL & HSIL & SCC \\
\hline 1 & Edelman et $\mathrm{al}^{6}$ & 1995 & New York & 29,295 & 13.2 & 9.9 & 2.5 & 0.6 & 0.2 \\
\hline 2 & Mufti et al7 & $2000-2012$ & Saudi Arabia & 15721 & 14.52 & 11.48 & 2.2 & 0.8 & 0.06 \\
\hline 3 & Banik et al 8 & 2010 & Bangladesh & 1699 & 8.18 & 0.18 & 6.36 & 1.18 & 0.35 \\
\hline 4 & Marahatta ${ }^{9}$ & $2010-2012$ & Nepal & 1751 & 1.14 & 0.45 & 0.85 & 0.28 & - \\
\hline 5 & Maryam et al ${ }^{10}$ & 2007 & Tehran & 13315 & 1.18 & 0.63 & 0.21 & 0.13 & 0.2 \\
\hline
\end{tabular}

The prevalence of epithelial abnormality with in India varies from 1.32 in Ahmedabad to 25\% in Guwahati. North Malabar of Kerala shows a prevalence of $2.42 \%$ in a study conducted there In a study conducted in Kannur of Kerala the prevalence was $2.15 \%$.

\begin{tabular}{|c|c|c|c|c|c|c|c|c|c|}
\hline \multirow{2}{*}{ No. } & \multirow{2}{*}{ Author } & \multirow{2}{*}{ Year } & \multirow{2}{*}{ Place } & \multirow{2}{*}{$\begin{array}{c}\text { No. of } \\
\text { Patients }\end{array}$} & \multirow{2}{*}{\begin{tabular}{|c|} 
Total \\
Prevalence (\%) \\
\end{tabular}} & \multicolumn{4}{|c|}{ Epithelial abnormality (\%) } \\
\hline & & & & & & ASC-US & LSIL & HSIL & SCC \\
\hline 1 & Tiwari et al 11 & $2007-2008$ & Delhi & 100 & 22.5 & 17.5 & 2.5 & 2.5 & - \\
\hline 2 & Alakananda et al ${ }^{12}$ & $2015-16$ & Guwahati & 280 & 25 & 12.3 & 3 & 7 & 3 \\
\hline 3 & Kothari et al 13 & $1998-2010$ & Ahmedabad & 36740 & 1.32 & 0.13 & 0.83 & 0.31 & 0.05 \\
\hline 4 & Patel et al ${ }^{14}$ & 2014 & Gujarat & 1808 & 4.65 & 2.9 & 0.6 & 0.6 & 0.3 \\
\hline 5 & Misra et al ${ }^{15}$ & 1971-2005 & Lucknow & 36484 & 7.8 & - & 5.5 & 1.6 & 0.6 \\
\hline 6 & Bamanikar16 & 2011-2013 & Pune & 498 & 5.36 & 2.32 & 1.96 & 0.36 & 0.72 \\
\hline 7 & Nair ${ }^{17}$ & $2012-2013$ & Malabar & 2028 & 2.42 & 0.15 & 1.58 & 0.49 & 0.2 \\
\hline 8 & Thomas EE et al 18 & $2014-2015$ & Kannur & 3059 & 2.15 & 0.26 & 1.01 & 0.88 & - \\
\hline \multirow{2}{*}{9} & \multirow{2}{*}{ Present study } & \multirow{2}{*}{$2017-2018$} & \multirow{2}{*}{ Kottayam, Kerala } & 240(camp) & 1.25 & - & 1.25 & - & - \\
\hline & & & & 240(hosp.) & 2.5 & 0.80 & 0.80 & 0.80 & - \\
\hline
\end{tabular}


The most common epithelial abnormality in camp population was LSIL (1.25\%), and in hospital population ASCUS, LSIL and HSIL shows equal incidence ( $0.80 \%$ each). This is similar to studies conducted in S. Africa, Bangladesh, Nepal and in other places of India - Ahmedabad, Lucknow, Malabar and Kannur, where LSIL was the predominant abnormality. No case of invasive carcinoma was found in this study. This might be because women with higher grades of epithelial abnormality may present late and go directly for surgical intervention.

\section{Limitations of The Study}

The sample size of the study was small. As follow up of these patients could not be carried out, the final outcome was not known. No correlation of cervical abnormalities with clinical symptoms was done. Use of liquid-based cytology methods may further reduce the number of unsatisfactory smears, but is not cost effective in our set up.

\section{CONCLUSION}

The prevalence of epithelial abnormality in camp population is $1.25 \%$ and, in the hospital, population is $2.5 \%$. The common cytopathological pattern seen in both camp and hospital population was NILM, non-specific inflammation, specific inflammation including bacterial vaginosis and candidiasis. Among the epithelial abnormalities detected, in the camp population it was LSIL (1.25\%) and in the hospital population it was ASC-US, LSIL and HSIL (0.80\%) each. Although diverse epithelial abnormalities were detected in the hospital population, presence of a relatively high proportion of LSIL cases in the asymptomatic camp population warrants screening of the general population.

Hence on a routine basis, every woman above the age of 21 should have a Pap smear done and this must be continued even in post-menopausal period. We propose that larger studies are required to estimate the pattern of cervical cytological abnormalities along with detection of common HPV strains.

\section{ACKNOWLEDGEMENT}

I express my heartfelt thanks and gratitude to Dr. Sankar S, Head of the Department, Department of Pathology, Government Medical College, Kottayam and my Guide Dr. Sunitha Balakrishnan for their support and help. I am thankful to all my teachers in the Department of Pathology, Government Medical College, Kottayam as well as fellow postgraduate students for their co-operation, help and encouragement.

\section{REFERENCES}

[1] Patel MM, Pandya AN, Modi J. Cervical Pap smear study and its utility in cancer screening, to specify the strategy for cervical cancer control. National Journal of Community Medicine 2011;2(1):49-51.

[2] Sarma U, Mahanta J, Talukdar K. Pattern of abnormal cervical cytology in women attending tertiary hospital. Int J Sci Res Pub 2012;2(12):1-4.
[3] Nandakumar A, Anantha N, Venugopal TC. Incidence, mortality and survival in cancer of the cervix in Bangalore, India. British Journal of Cancer 1995;71(6):1348-52.

[4] Ali F, Kuelker R, Wassie B. Understanding cervical cancer in the context of developing countries. Annals of Tropical Medicine and Public Health 2012;5(1):3-15.

[5] Gönen M. A review of: statistical methods in diagnostic medicine. In: Zhou XH, Obuchowski NK, McClish DK, eds. Journal of Biopharmaceutical Statistics. $2^{\text {nd }}$ edn. Hoboken: Wiley-Blackwell 2012: p. 612-4.

[6] Nance KV. Evolution of Pap testing at a community hospital: a ten year experience. Diagn Cytopathol 2007;35(3):148-53.

[7] Marahatta R, Bhattarai S. Value of conventional cervical cytology as a screening test for cervical cancer. Orig Artic Nepal Med Coll J 2013;15(2):223-7.

[8] Edelman M, Fox AS, Alderman EM, et al. Cervical Papanicilaou smear abnormalities in inner city Bronx adolescents: prevalence, progression and immune modifiers. Cancer 1999;87(4):184-9.

[9] WHO. The World Health report 1995 - bridging the gaps. WHO, 2018 [cited 14 November 2018]. http://www.who.int/whr/1995/en/.

[10] Bukhari MH, Saba K, Qamar S, et al. Clinicopathological importance of Papanicolaou smears for the diagnosis of premalignant and malignant lesions of the cervix. Journal of Cytology 2012;29(1):20-5.

[11] Thomas EE, Kumaran JA. Profile of PAP smears done in a tertiary centre in North Kerala. International Journal of Community Medicine Public Health 2018;5(5):19749.

[12] Tiwari A, Kishore J, Tiwari A. Perceptions and concerns of women undergoing Pap smear examination in a tertiary care hospital of India. Indian J Cancer 2011;48(4):477-82.

[13] Mody DR. Glandular cell abnormalities. Part 1, Section 4. In: Mody DR, edr. Diagnostic pathology cytopathology. Salt Lake City (Utah): Amirsys Publishing Inc., 2014: p. 2-28.

[14] Alakananada, Sarma U, Biswas I. Histopathological correlation with cervical cytology. IOSR J Dent Med Sci 2016;15(11):2279-861.

[15] Patel CB, Shah PC, Bhagat VM. A role of cervical Pap smear as a screening tool in diagnosis of lesions of cervix-a one-year study. Int J Med Sci Public Heal 2016;5(9):1841-5.

[16] Tailor HJ, Patel PR, Bhagat VM. Study of cervical pap smears in a tertiary care hospital of south Gujarat, India. Int J Res Med Sci 2016;4(1):286-8.

[17] Nair G, Shamsuddin F, Narayanan T, et al. Cytopathological pattern of cervical Pap smears - a study among population of North Malabar in Kerala. Indian Journal of Pathology and Oncology 2016;3(4):552-7.

[18] Afrakhteh M, Khodakarami N, Moradi A, et al. A study of 13315 Papanicolau smear diagnoses in Shohada hospital. J Family Reprod Health 2007;1(2):75-9. 